\title{
Beyond magnitude: Judging ordinality of symbolic number is unrelated to magnitude comparison and independently relates to individual differences in arithmetic
}

\author{
Celia Goffin, The University of Western Ontario
}

Supervisor: Dr. Daniel Ansari, The University of Western Ontario

A thesis submitted in partial fulfillment of the requirements for the Master of Science degree in Psychology

(C) Celia Goffin 2015

Follow this and additional works at: https://ir.lib.uwo.ca/etd

Part of the Psychology Commons

\section{Recommended Citation}

Goffin, Celia, "Beyond magnitude: Judging ordinality of symbolic number is unrelated to magnitude comparison and independently relates to individual differences in arithmetic" (2015). Electronic Thesis and Dissertation Repository. 2952.

https://ir.lib.uwo.ca/etd/2952

This Dissertation/Thesis is brought to you for free and open access by Scholarship@Western. It has been accepted for inclusion in Electronic Thesis and Dissertation Repository by an authorized administrator of Scholarship@Western. For more information, please contact wlswadmin@uwo.ca. 
BEYOND MAGNITUDE: JUDGING ORDINALITY OF SYMBOLIC NUMBER IS UNRELATED TO MAGNITUDE COMPARISON AND INDEPENDENTLY RELATES

TO INDIVIDUAL DIFFERENCES IN ARITHMETIC

(Thesis format: Monograph)

by

Celia Goffin

Graduate Program in Psychology

A thesis submitted in partial fulfillment of the requirements for the degree of Master of Science

The School of Graduate and Postdoctoral Studies

The University of Western Ontario

London, Ontario, Canada

(C) Celia Goffin 2015 


\begin{abstract}
In the field of numerical cognition, ordinality, the sequence of numerals, has received less attention than cardinality, the number of items in a set. Therefore it is unclear whether numerical effects generated from ordinality and cardinality tasks are associated, and whether they relate to math achievement and more domain-general variables in similar ways. To address these questions, sixty adults completed ordinality, cardinality, visual-spatial working memory, inhibitory control and math achievement tasks. The numerical distance effect from the cardinality task and reverse distance effect from the ordinality task were reliable but not associated with one another. Additionally, both distance effects predicted independent unique variance in math scores, even when visual-spatial working memory and inhibitory control were included in the regression model. These findings provide support for dissociation in the mechanisms underlying cardinal and ordinal processing of number symbols and thereby highlight the critical role played by ordinality in symbolic numerical cognition.
\end{abstract}

\title{
Keywords
}

ordinality, cardinality, number comparison, numerical cognition, arithmetic achievement 


\section{Acknowledgments}

I would like to thank Dr. Daniel Ansari. Daniel is an incredibly supportive and knowledgeable supervisor and I have learned so much from him over the last few years. His enthusiasm for research is very inspiring and contagious, and I feel that I have grown as a researcher through his guidance. I will always be hugely grateful for all of the advice and mentorship I have received from Daniel.

Thank you to Dr. Ian Lyons for his expertise in all things related to ordinality (including the ordinality measure). I would also like to thank the other members of the Numerical Cognition Lab: Moriah Sokolowski, Anna Matejko, Dr. Stephanie Bugden, and Bea Goffin for all of the feedback and encouragement they have given. Coming to work in such a supportive and collaborative environment has been invaluable to me.

Finally, thank you to my family and Will for their understanding, love and support. I am so grateful for the encouragement during both the stressful and happy moments. 


\section{Table of Contents}

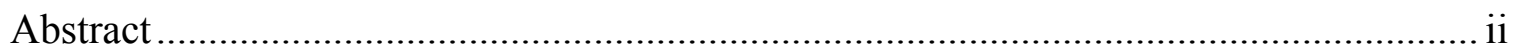

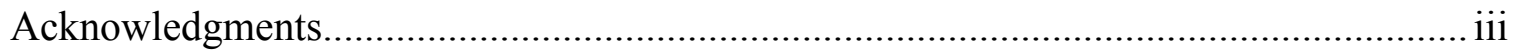

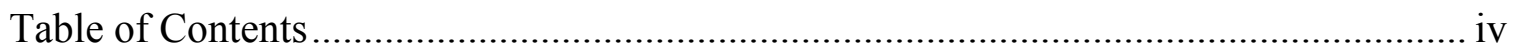

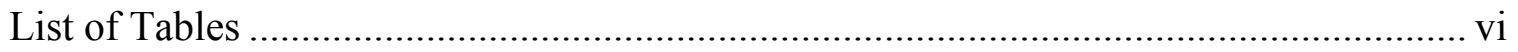

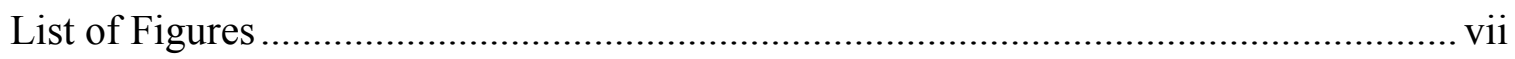

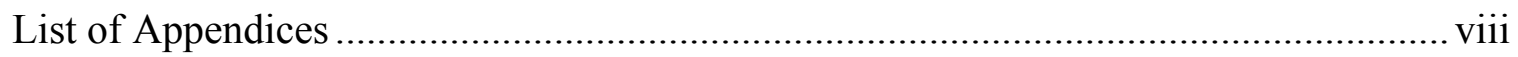

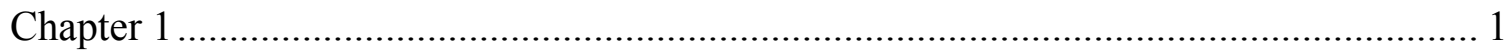

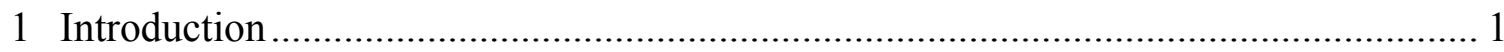

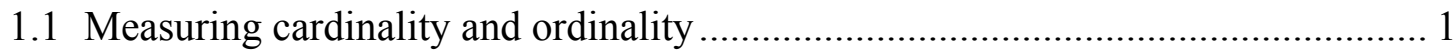

1.2 Shared mechanisms for ordinality and cardinality? ...................................... 2

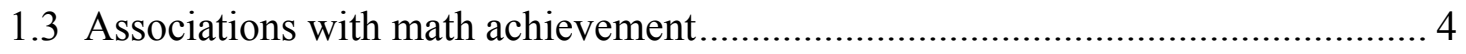

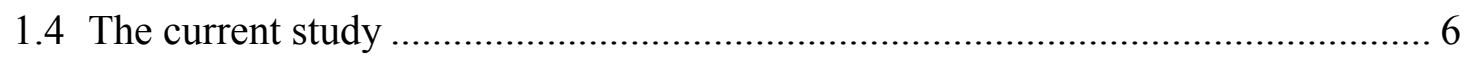

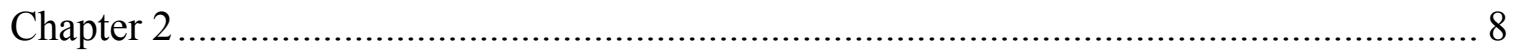

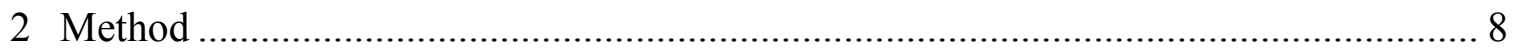

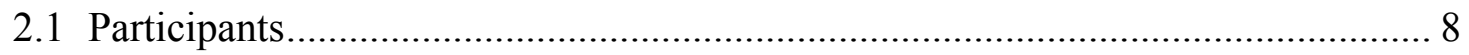

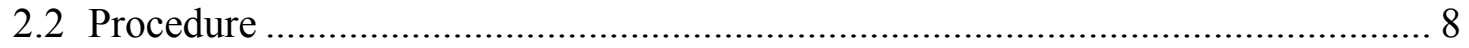

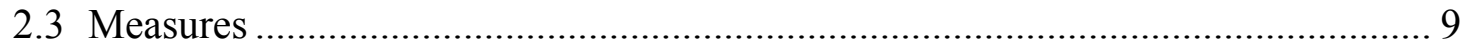

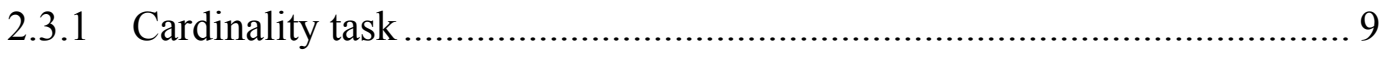

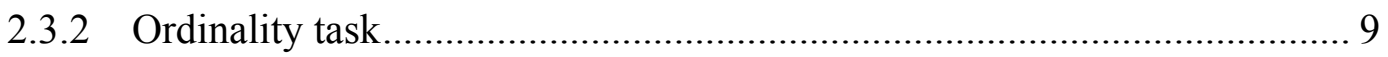

2.3.3 Math achievement .......................................................................... 10

2.3.4 Inhibitory control ...................................................................... 10

2.3.5 Visual-spatial working memory.................................................. 11

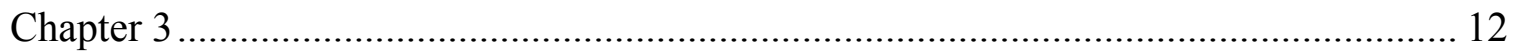

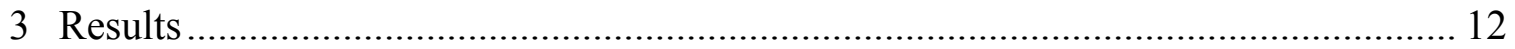


3.1 Numerical Distance Effect........................................................................... 12

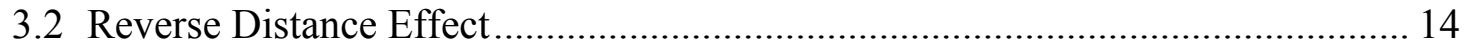

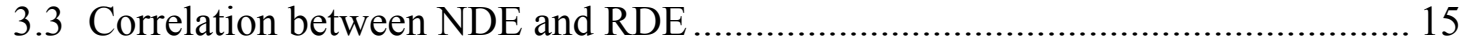

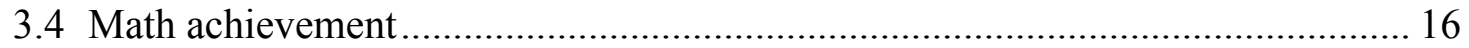

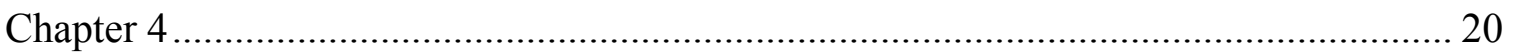

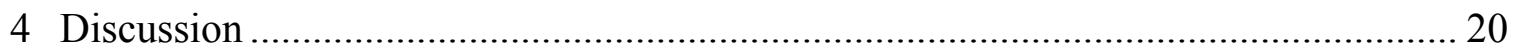

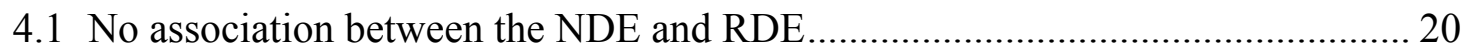

4.2 Cardinality and ordinality contribute uniquely to math achievement skills ......... 22

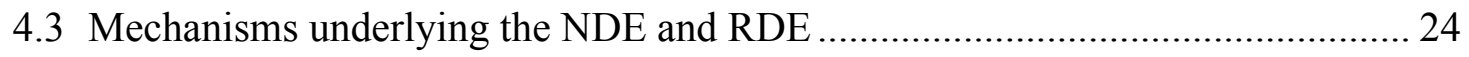

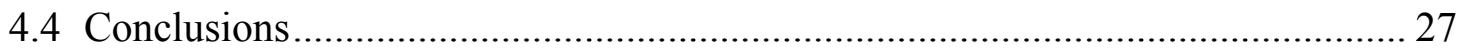

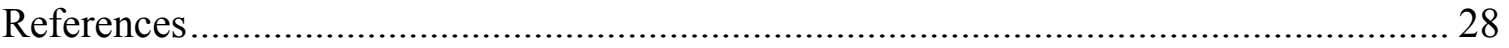

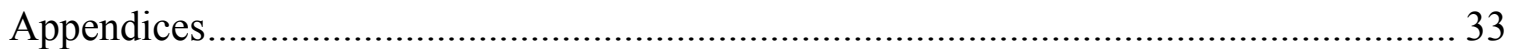




\section{List of Tables}

Table 1: Correlations between the NDE, RDE and visual-spatial working memory, the contrast measure from the inhibition task and the scaled errors from the inhibition task. ..... 16

Table 2: Correlations between the NDE, RDE and the standardized scores for Math Fluency, Calculation and the composite math score........................................ 16

Table 3: Correlations between the accuracy NDE, RDE and standardized scores for Math Fluency, Calculation, and the composite score. No significant associations were found. ..... 17

Table 4: Correlations between the performance measures from the cardinality and ordinality task and standardized scores for math achievement. 19 


\section{List of Figures}

Figure 1: Significant positive correlation between block 1 NDE and block 2 NDE............ 13

Figure 2: Significant positive correlation between block 1 RDE and block 2 RDE............ 15

Figure 3: Correlation between the NDE and the standardized composite math achievement score and RDE and the standardized composite math achievement score. A smaller NDE and RDE was associated with increased math achievement performance. ................................ 17 


\section{List of Appendices}

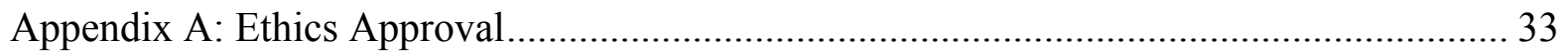

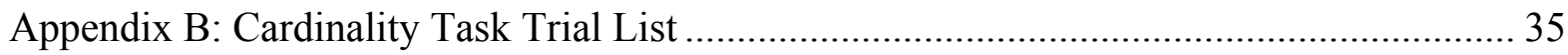

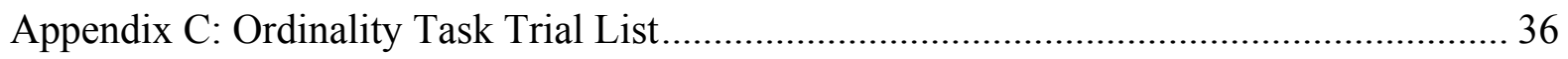




\section{Chapter 1}

\section{Introduction}

Number symbols have been studied extensively as representations of specific quantities (e.g., Nieder \& Dehaene, 2009). For example, much research has investigated how children learn that the Arabic symbol "5" refers to five items (for a review see Ansari, 2008). This referent of symbolic numbers is called the symbol's cardinality, or the number of items in a set that a symbol represents (e.g., Lyons \& Beilock, 2013).

An important and often overlooked attribute of symbolic numbers is that they not only have symbol-magnitude associations, as in cardinality, but also symbol-symbol relationships, or ordinality (e.g., Nieder, 2005; Vogel, Remark, \& Ansari, 2015). Ordinality refers to the sequencing of number symbols, for example five is the fifth number - it comes after four and before six (Lyons \& Beilock, 2013). In order to fully characterize the cognitive nature of symbolic number processing it is critical to learn more about the differences and similarities between ordinal and cardinal processing of symbolic number. This has important implications for models of symbolic number processing and how children learn to process numerical symbols.

\subsection{Measuring cardinality and ordinality}

Cardinality - or numerical magnitude - is commonly measured using a number comparison task. In this task, participants are presented with two numbers and asked to choose the larger or smaller of the two. This task generates a behavioural signature called the numerical distance effect (NDE), in which participants are faster and more accurate at choosing the correct number as the numerical distance between the target numbers 
increases (Moyer \& Landauer, 1967). The NDE has been replicated in numerous studies since its first account (e.g., Holloway \& Ansari, 2008; Lonnemann, Linkersdörfer, Hasselhorn, \& Lindberg, 2011; Maloney, Risko, Preston, Ansari, \& Fugelsang, 2010; Sasanguie, De Smedt, Defever, \& Reynvoet, 2012; Sasanguie, Defever, Van den Bussche, \& Reynvoet, 2011; Swanson, 2011).

To measure ordinality, participants are typically presented with three number symbols and asked to indicate whether the numbers are in the correct ascending order (e.g., 13 5), or not in order (e.g., 15 3; Lyons \& Beilock, 2011). Alternatively, two symbols may be presented and participants asked whether the digits are in ascending (e.g., 1 3), or descending (e.g., 3 1) order ( Turconi, Campbell, \& Seron, 2006). The reaction time and accuracy data from such ordinality tasks has been found to generate a so-called reverse distance effect (RDE). It is called the reverse distance effect because it exhibits a relationship that is opposite to that of the NDE revealed during number comparison: decreased accuracy and increased reaction time as the numerical distance between the target numbers increases (Franklin \& Jonides, 2009). The RDE has been replicated with adult data using the three digit task (Lyons \& Beilock, 2013) and has also been demonstrated in the two digit task by Turconi and colleagues (2006).

\subsection{Shared mechanisms for ordinality and cardinality?}

It is unclear whether ordinality and cardinality tap into different cognitive mechanisms and neuronal circuits. There has been some research to indicate that magnitude comparison and numerical ordering may be underpinned by different brain

processes. Turconi, Jemel, Rossion, and Seron (2004) used event-related potentials (ERPs) and demonstrated a dissociation between cardinality and ordinality processes in 
the time course of the P2 component from electrodes close to the left parietal cortex. Complementary to Turconi and colleagues' (2004) results, Lyons and Beilock (2013), in a functional MRI (fMRI) study using a symbolic magnitude comparison task and an ordering task, no overlapping regions of activation were found.. However, in contrast to Turconi et al. (2004) and Lyons and Beilock (2013), Franklin and Jonides (2009) found common activation of the intraparietal sulcus (IPS) for both the magnitude comparison and ordering tasks. More specifically, the IPS demonstrated both a neural distance effect for the comparison task and a reverse of this distance effect for the ordering task. IPS activation was greater for smaller distances than larger distances in the comparison task, but greater for larger distances than smaller distances for the ordinality task. Thus the neural data concerning the mechanisms underlying cardinality and ordinality are presently inconclusive.

At the behavioural level, Turconi et al. (2006) asked participants either to judge the relative magnitude or order of pairs of single digits. They found different behavioural signatures depending on how the participants were asked to process the symbolic numerical stimuli: an NDE for the comparison task and an RDE for ascending pairs (e.g. 12 ) in the ordering task. This finding of a divergence in the behavioural signatures generated from the two tasks provides support for different underlying processes. However, it is important to note the demonstration of different task effects does not preclude the existence of shared mechanisms. In other words, it is still possible that the different effects for ordinality and comparison are significantly correlated with one another, which would suggest a common mechanism that gives rise to different effects depending on the task context. 
The only study that has directly correlated judgements of symbolic ordinality and cardinality with one another focussed on grade one students. Specifically, using a paradigm similar to that employed by Turconi et al. (2006), Vogel et al. (2015) demonstrated an absence of a correlation between symbolic comparison and ordering performance in grade one children. Given that these data were obtained from young children, they leave unanswered the question of whether such an association emerges over developmental time or not.

\subsection{Associations with math achievement}

Although it is currently unknown whether there are common mechanisms underlying symbolic cardinality and ordinality, both are thought to be important for the development of more complex mathematical skills, such as arithmetic. Numerous studies have shown that the NDE from the symbolic number comparison task is related to math achievement in both adults and children (for a review see: De Smedt, Noël, Gilmore, \& Ansari, 2013). A significantly smaller body of emerging evidence also demonstrates that ordering abilities are related to calculation skills in adults (Lyons \& Beilock, 2011). This then raises the question of whether ordinality and cardinality play equally important roles in more complex mathematical skills.

In children it has been demonstrated that magnitude comparison and ordering skills relate differently to math achievement. Vogel and colleagues (2015) found that performance on a comparison task correlated significantly with math achievement in grade one children, while ordering abilities did not. Furthermore, Lyons, Price, Vaessen, Blomert and Ansari (2014) captured a switch in the relative contributions to math achievement of cardinality and ordinality between grades one through six. Specifically, 
symbolic magnitude comparison predicted math achievement better than ordinality in the earlier grades, whereas ordinality was the stronger unique predictor in later grades. Thus, from the developmental literature it appears that ordinality and cardinality may relate differently to more complex mathematics, which may indicate that different mechanisms underpin them.

In adults there is a lack of research addressing the relationship between ordinality, cardinality and math achievement. Lyons and Beilock (2011) found that a performance measure (a combination of error rate and reaction time) derived from an ordinality task fully mediated the relationship between a non-symbolic (dot) magnitude comparison task and arithmetic. This finding provides evidence of an important role for ordering abilities in adult mathematical skills. In support of this behavioural finding, Knops and Willmes (2014) demonstrated that clusters of activation in regions of the right IPS were correlated with both ordering and arithmetic tasks; however a magnitude comparison task was not included. To date, there is no adult study that has looked at both symbolic comparison and ordering, and their relationships with math achievement.

Additionally, there has been no study relating the RDE to math performance. The $\mathrm{RDE}$ is a behavioural signature that differentiates ordering from magnitude comparison, a task which conversely shows a canonical distance effect (Turconi et al., 2006). The NDE is considered a measure of magnitude processing, and has been associated with math achievement in the literature (De Smedt et al., 2013). The NDE is often considered a measure of the precision of the number representation system (De Smedt, Verschaffel, \& Ghesquière, 2009; Holloway \& Ansari, 2009). Accordingly, the NDE has been shown to decrease across development (Holloway \& Ansari, 2008; Sekuler \& Mierkiewicz, 1977). 
Moreover evidence from both children and adults has consistently demonstrated that a smaller NDE is associated with increased math achievement scores (e.g. Holloway \& Ansari, 2009; DeSmedt et al., 2009; Castronovo \& Göbel, 2012). As is the case for the NDE, the RDE could be considered a task-specific measure of ordering abilities, and therefore it is important to probe whether there exists an association between this effect and math achievement. In addition, in the context of investigating the similarities and differences between cardinal and ordinal processing of number symbols, it is critical to investigate whether the NDE and RDE explain shared or independent variance in individual differences in math achievement.

\subsection{The current study}

From the available neural and behavioural literature on ordinality and cardinality, it is unclear whether different mechanisms underlie these constructs in adults. Furthermore, it is unclear whether both ordinality and cardinality are independently related to more complex mathematical skills. More specifically, we do not know whether 1) the RDE is related to math achievement and 2) if the RDE is related to math achievement, whether it predicts variance independently of the variance accounted for by the NDE. Before assessing any relationships between cognitive measures and their association with other variables, such as math achievement, it is important to establish their reliability (e.g., Maloney et al., 2010; Sasanguie et al., 2011). Consequently, we first assessed the split-half reliability of the ordinality and cardinality tasks by including two identical blocks within these tasks. Following the evaluation of reliability, we assessed the idea of common mechanisms underlying cardinality and ordinality, and the relationship of these abilities with math achievement. 
Against the background of studies that find a different contribution of ordering and comparison skills to math abilities across development (Lyons et al., 2014; Vogel et al., 2015), we would predict that ordinality and cardinality also relate differently to math in adults. More specifically, based on the pattern of findings by Lyons and colleagues (2014), we would expect ordinality to be a stronger predictor than cardinality for math achievement in adults. Along the same lines, we also hypothesize that there exist different mechanisms underlying the ordinal and cardinal processing of symbolic numerical stimuli, and therefore that performance on the ordering and comparison tasks will not correlate. Finally, in the present study we included measures of visual-spatial working memory and inhibitory control - domain-general variables that have been shown to correlate with individual differences in math achievement (Dumontheil \& Klingberg, 2012; Gilmore et al., 2013). The inclusion of these domain-general variables will allow us to determine whether specific numerical processes (cardinality and ordinality) predict math achievement over and above the constructs of working memory and inhibitory control. 


\section{Chapter 2}

\section{Method}

\subsection{Participants}

Sixty-eight adult English-speaking participants were recruited from the University of Western Ontario in London, Ontario, Canada. The first six participants were not included, as we could not obtain complete data sets due to computer errors. One participant was removed from the study because of a self-reported neural anomaly and one additional participant was removed because they did not comply with task instructions. Therefore, a total of 60 participants were included in the analyses (22 males; $M_{\text {age }}=23.48$ years). The research protocol was approved by the University's Research Ethics Board.

\subsection{Procedure}

Each participant completed all tasks during a 1.5 hours individual testing session. The list of tasks follows: ordinality, number comparison, math achievement, visualspatial working memory, inhibitory control, size congruity and priming naming. The size congruity and priming naming tasks were not included for the purposes of the current paper. The order of task administration was counterbalanced across participants. Stimuli for the computerized numerical tasks were presented on a Dell laptop with a 13-inch screen using E-prime 2 software (Psychological Software Tools, Pittsburgh, PA, USA). 


\subsection{Measures}

\subsubsection{Cardinality task}

Two digits taken from 1-9 were presented simultaneously on a black background with white font (Courier new, size 72 font). Each trial consisted of a fixation dot (1000ms) and two target numbers (5000ms, or shorter if the participant made a response). Numbers were chosen so that there were 12 trials for each of the six distances (1-6) between the target numbers. See Appendix B for a complete list of trials used. Distance was the absolute difference between the two target numbers. Thus there were 72 trials, which were randomly cycled through twice for a total of 144 trials per block. Two blocks were used, for a total of 288 trials for a complete run of the paradigm. Participants were asked to decide which of the two target numbers was larger, and to make their response on the keyboard. The paradigm took approximately seven minutes to complete.

\subsubsection{Ordinality task}

In this task, three digits (size 27 Calibri font) taken from 1-9 were presented in the center of the screen in white font on a black background. Each trial consisted of a blank screen $(167 \mathrm{~ms})$, followed by the simultaneous presentation of the three target numbers (which remained on the screen until participants made a response), blank screen (167ms), fixation screen with three empty boxes where the next number stimuli would appear $(1500 \mathrm{~ms})$ and a final blank screen $(167 \mathrm{~ms})$. There were sixty trials which were randomly cycled through twice, for a total of 120 trials per block. On half of the trials the numbers were in the correct ascending order; on half of the trials the numbers were not in order. Numerical distances of one, two, or three were used for the ordinality task. Distance was defined as the absolute difference between the maximum and median numbers, and 
median and minimum numbers $[\max (n)-\min (n)] / 2$; therefore this difference was equal regardless of the order of the numbers. Therefore the combinations of possible numbers were as follows: seven trials for distance 1 , five trials for distance 2 , and three trials for distance 3. See Appendix C for a complete list of trials. Each combination was presented twice in order and twice out of order for a total of 60 trials, which were randomly cycled through twice per block. Two blocks were used, for a total of 240 per a complete run of the task. Participants were asked to decide whether the target numbers were in the correct ascending order, or not in order, and to make their response on the keyboard. The assignment of the meaning of the buttons ("in order" or "not in order") was randomized across participants. The task took approximately ten minutes to complete.

\subsubsection{Math achievement}

Math achievement was measured using two subtests from the Woodcock Johnson III Tests of Achievement: Calculation and Math Fluency (Woodcock, McGrew, \& Mather, 2001). The Calculation subtest is an untimed measure of math achievement that requires participants to solve math problems that increase in difficulty. In the Math Fluency subtest, participants answered simple arithmetic problems as quickly as possible within a three-minute time period. The scores for our sample on these measures were as follows: Calculation standard score: mean $=114.38, S D=16.12$, Math Fluency standard score: mean $=107.97, S D=13.95$, Composite score: mean $=115.35, S D=16.45$.

\subsubsection{Inhibitory control}

Inhibitory control was measured with the Color-Word Interference Test from the Delis-Kaplan Executive Function System (D-KEFS; Delis, Kaplan \& Kramer, 2001). In this task, participants were asked to read sequences of colours and colour words as 
quickly and accurately as possible. In the inhibition condition, colour words were presented in a different colour of ink (e.g., "green" presented in red ink) and participants needed to inhibit reading the word and instead name the ink colour. Scaled scores on the D-KEFS have a mean of 10 and a standard deviation of 3. Performance on the inhibition measures were as follows: inhibition time score scaled by age category, mean $=11.73$, $S D=2.76$, inhibition contrast score, mean $=11.78, S D=1.98$, and inhibition errors scaled $=10.68, S D=1.86$. The inhibition contrast score was calculated by subtracting the age-scaled colour naming score from the scaled inhibition score, while the inhibition errors scaled score gives a percentile ranking of the age-scaled number of errors made on the inhibition condition.

\subsubsection{Visual-spatial working memory}

The visual-spatial working memory task - Odd One Out - was taken from the Automated Working Memory Assessment (AWMA; Alloway, 2007). In this computerized task, participants were presented with increasing series of three shapes in boxes. They were instructed to first point at the 'odd one out' shape (the one shape that differs from the other two), and at the end of the trial were asked to recall the locations of all 'odd one out' shapes. At the beginning of the task participants were only required to remember the location of one shape, and the length of the sequence of locations to be recalled increased up to seven sets of shapes. The standardized score mean on the working memory task was: standardized score mean $=102.55, S D=15.91$. 


\section{Chapter 3}

\section{Results}

\subsection{Numerical Distance Effect}

Accuracy for the number comparison task was $96.0 \%(S D=0.03)$. For the reaction time $(\mathrm{RT})$ data, trials that differed $+/$ - three standard deviations from the individual participant's mean RT were removed from the analysis, as were trials less than $100 \mathrm{~ms}$ and greater than $5000 \mathrm{~ms}$. The NDE for RT from the cardinality task was calculated with the following formula:

$N D E_{R T}=\left(\operatorname{meanRT} T_{1,2,3}-\operatorname{meanRT}_{4,5,6}\right) /$ meanRT $T_{1,2,3,4,5,6}$, where $4,5,6$ and $1,2,3$ are the large distances and small distances between the target numbers, respectively. Only correct trials were included in this calculation. A significant NDE was found, marked by a significantly lower RT for the large distances $(M=445.54, S D=88.44)$ compared to the small distances $(M=492.48, S D=104.65)$, mean NDE $=0.097, S D=0.039 ; t(59)=$ 19.06, $p<.001$. We also obtained a significant NDE for the accuracy data using the same formula as the RT NDE (one participant was removed as their mean accuracy NDE was more than three standard deviations from the group mean accuracy NDE), mean NDE $=$ $0.05, S D=0.03 ; t(58)=-11.42, p<.001$. Participants were significantly more prone to error with the smaller numerical distances relative to the larger distances.

We assessed the split-half reliability for the RT NDE by calculating an NDE value for block one and two separately, using the above formula. There was a significant NDE for block one and two, $t(59)=16.58, p<.001$ and $t(59)=17.17, p<.001$, respectively, that did not differ significantly across blocks, $t(59)=1.11, p=.270$. The 
NDE from the number comparison task was found to be reliable, demonstrated by a significant correlation between the NDE for blocks one $(M=0.10, S D=0.047)$ and two $(M=0.094, S D=0.042), r(58)=.563, p<.001$ (see Figure 1). For the NDE calculated from the accuracy data, there was also a significant correlation between block one (one outlier removed; $M=-0.055, S D=0.05 ; \mathrm{NDE}, t(58)=-9.28, p<.001$ ) and two (one outlier removed; $M=-0.047, S D=0.037$; NDE, $t(58)=-9.78, p<.001), r(56)=.418, p=$ $.001)$.

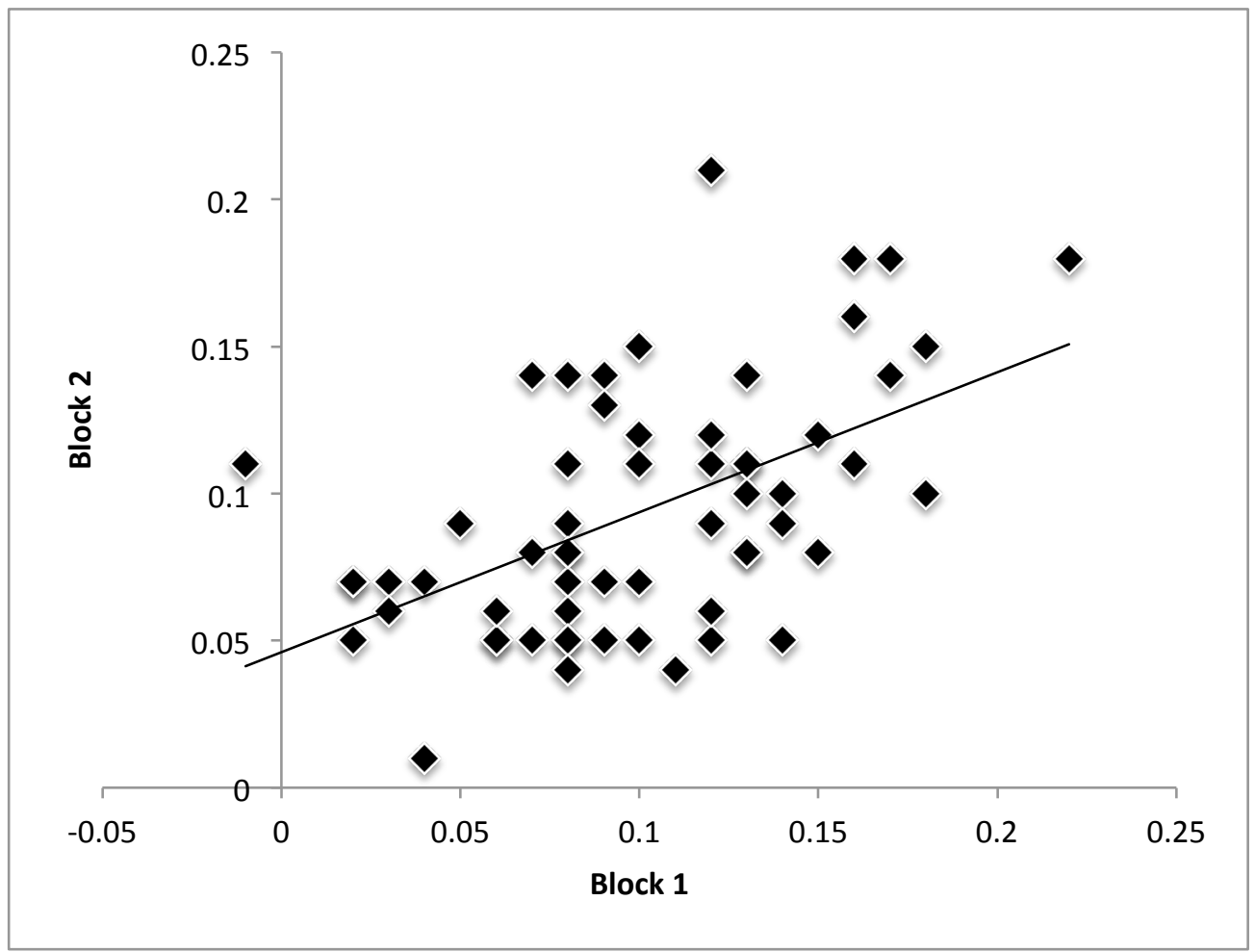

Figure 1: Significant positive correlation between block 1 NDE and block 2 NDE. 


\subsection{Reverse Distance Effect}

Mean accuracy for the in order trials from the ordinality task was $95.3 \%(S D=$ 0.04). The RDE for RT from the ordinality task was calculated using only correct trials that were in order. Consistent with the analysis of the NDE above, trials that differed more than $+/$ - three standard deviations from the participant's mean RT were removed, as were trials less than $100 \mathrm{~ms}$ and greater than $5000 \mathrm{~ms}$. As there was no significant difference between the average RT's for distances two and three, $t(59)=-1.67, p=.10$,

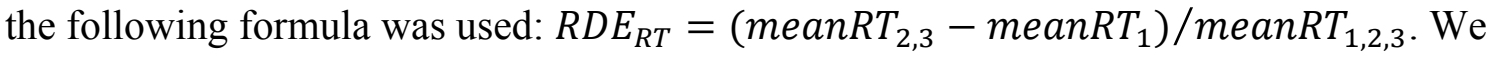
obtained a significant RDE, defined by a significantly higher RT for the large distances $(M=877.70, S D=318.70)$ compared to the small distance $(M=801.43, S D=260.63)$, mean $\mathrm{RDE}=0.082, S D=.084 ; t(59)=7.59, p<.001$. A significant $\mathrm{RDE}$ was calculated for the accuracy data using the same formula as the RT RDE (one outlier participant was removed), mean $\mathrm{RDE}=-0.03, S D=0.05 ; t(58)=-3.75, p<.001$. Participants made significantly more errors for the large distances between the three target numbers than they did for distance one.

The RT RDE split-half reliability was calculated by correlating RDE values from block one $(M=0.105, S D=0.101)$ and two $(M=0.052, S D=0.092)$ of the ordinality task. One participant was found to be an outlier (RDE values +/- three standard deviations from the group mean on block two) and thus was removed from the analysis. There was a significant RDE both in block one and two, $t(59)=8.06, p<.001$ and $t(58)=$ $4.36, p<.001$, although the RDE for block two was significantly smaller than for block one, $t(58)=3.61, p=.001$. The $\mathrm{RDE}$ was found to be reliable as revealed by a significant correlation of the effect between blocks one and two, $r(57)=0.38, p=.003$ (see Figure 
2). For the RDE calculated using the accuracy data, there was also a significant correlation between block one (two outliers removed; $M=-0.02, S D=0.05$; RDE, $t(57)=$ $-2.97, p=.004$ ) and two (one outlier removed; $M=-0.03, S D=0.07$; $\mathrm{RDE}, t(58)=-2.84$, $p=.006, r(56)=.273, p=.038)$.

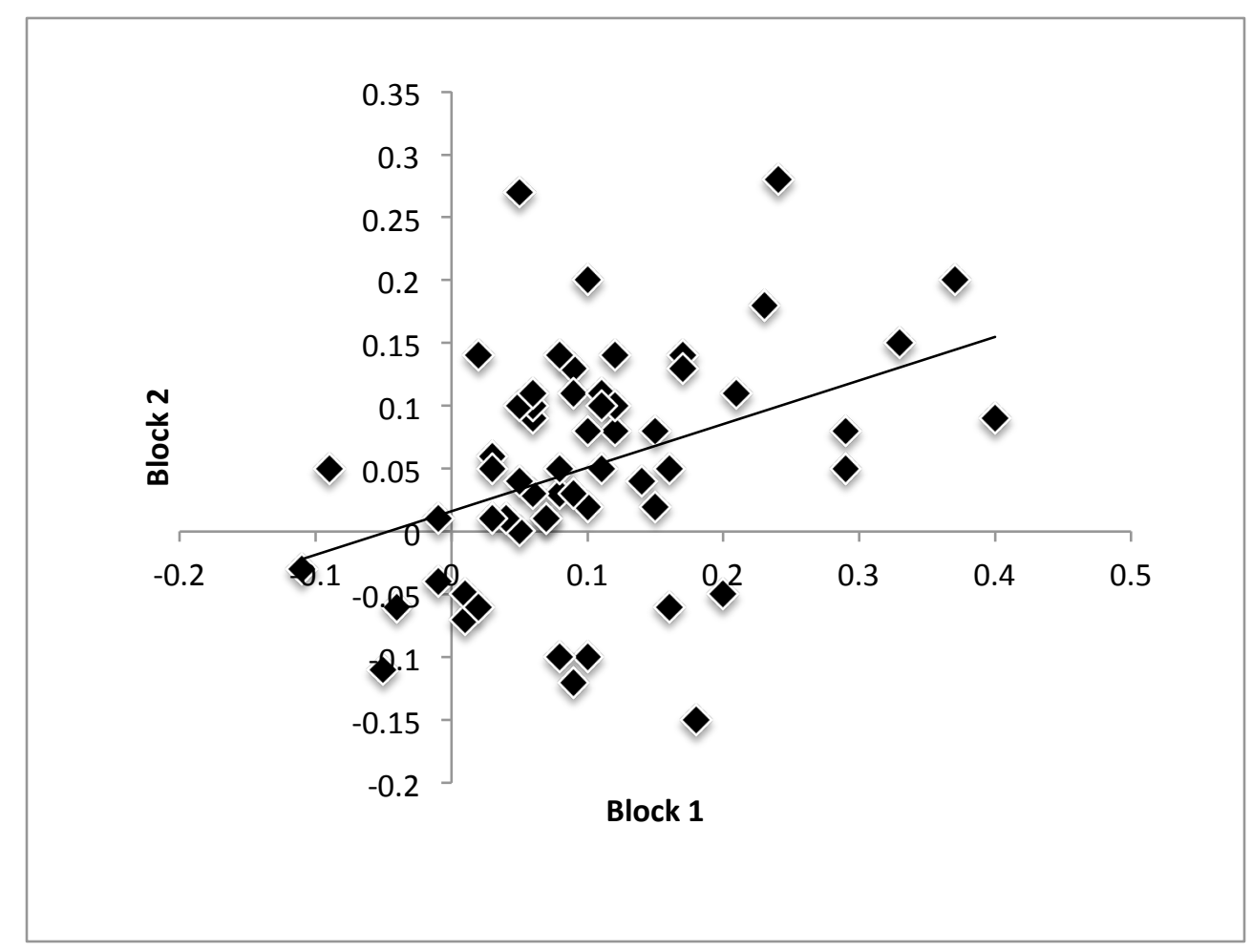

Figure 2: Significant positive correlation between block 1 RDE and block 2 RDE.

\subsection{Correlation between NDE and RDE}

We assessed the correlation between the NDE from the number comparison task and the RDE from the ordinality task. We did not find a significant association between the NDE and RDE, $r(58)=.171, p=.192$. The accuracy NDE and RDE were also not correlated with one another, $r(57)=0.043, p=.745$ Additionally, we did not find associations between the NDE and visual-spatial working memory or inhibition (contrast measure or errors; see Table 1). There were also no significant correlations between the 
RDE and visual-spatial working memory or inhibition measures (contrast measure or errors; see Table 1).

Table 1: Correlations between the NDE, RDE and visual-spatial working memory, the contrast measure from the inhibition task and the scaled errors from the inhibition task.

\begin{tabular}{lccc}
\hline & Working Memory & Inhibition Contrast & Inhibition Scaled Errors \\
\hline NDE & -.051 & -.016 & .107 \\
RDE & .004 & .250 & .038 \\
\hline
\end{tabular}

\subsection{Math achievement}

We next assessed whether differences in NDE and RDE scores related to performance on the two math achievement tasks. Both the reaction time NDE and RDE correlated significantly with standard scores for Math Fluency and Calculation, and the Composite Score for both of these measures (see Table 2 and Figure 3). The accuracy NDE and RDE did not correlate with math achievement (see Table 3).

Table 2: Correlations between the NDE, RDE and the standardized scores for Math Fluency, Calculation and the composite math score.

\begin{tabular}{lccc}
\hline & Math Fluency & Calculation & Composite \\
\hline NDE & $-.334^{* *}$ & $-.392^{* *}$ & $-.423^{* *}$ \\
RDE & $-.326^{*}$ & $-.468^{* *}$ & $-.473^{* *}$ \\
\hline
\end{tabular}

**Pearson correlation is significant at the 0.01 level (2-tailed).

* Pearson correlation is significant at the 0.05 level (2-tailed). 


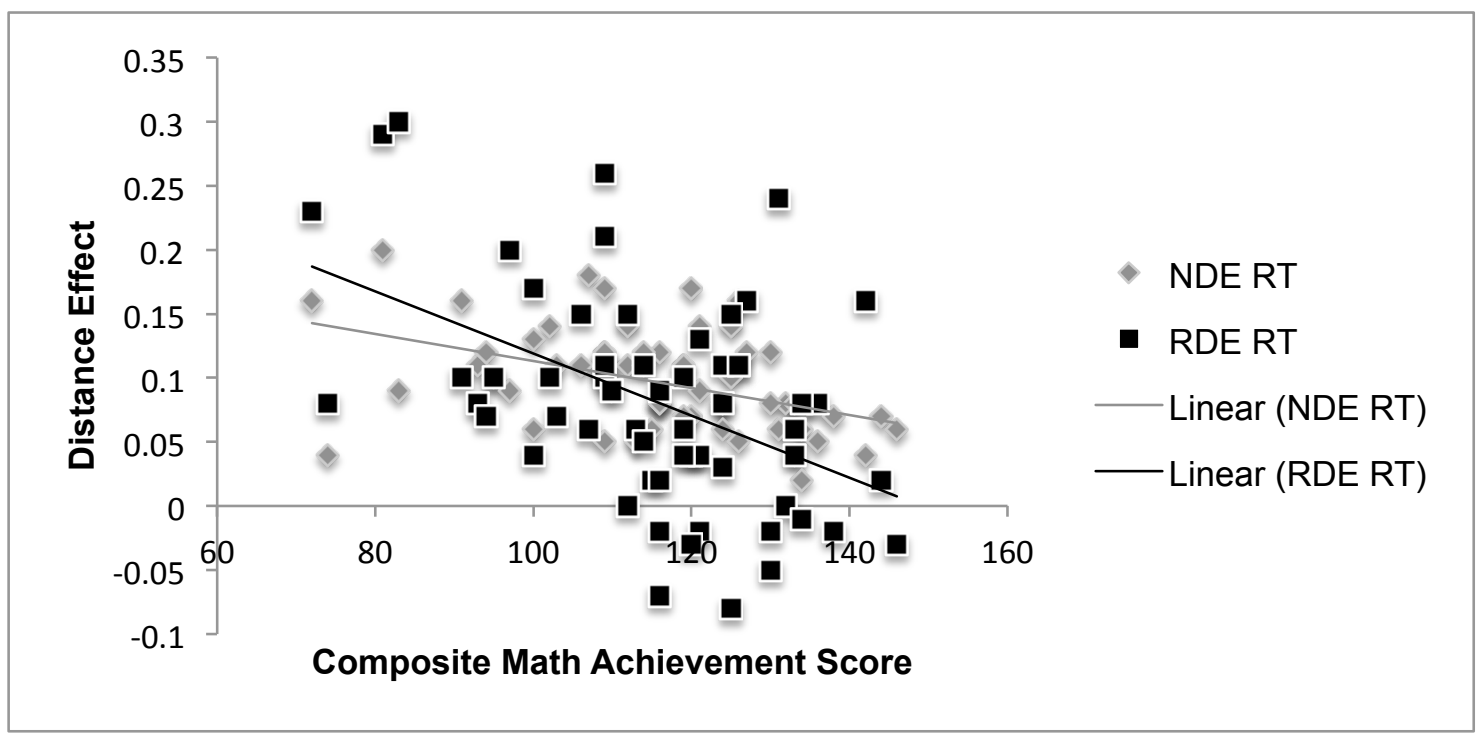

Figure 3: Correlation between the NDE and the standardized composite math achievement score (in grey) and RDE and the standardized composite math achievement score (in black). A smaller NDE and RDE was associated with increased math achievement performance.

Table 3: Correlations between the accuracy NDE, RDE and standardized scores for Math Fluency, Calculation, and the composite score. No significant associations were found.

\begin{tabular}{lccc}
\hline & Math Fluency & Calculation & Composite \\
\hline NDE Accuracy & .106 & .131 & .166 \\
RDE Accuracy & .195 & .102 & .166 \\
\hline
\end{tabular}

To determine whether the NDE and RDE were predicting unique variance in math achievement, both variables were entered as predictors in a multiple regression analysis. This model was able to predict $34.4 \%$ of the variance in the Composite math achievement 
scores, with both NDE and RDE predicting unique variance, $F(2,59)=14.97, p<.001$, $\beta_{\mathrm{NDE}}=-.352, p=.002, \beta_{\mathrm{RDE}}=-.413, p<.001$.

Out of the domain-general variables, only the scaled errors on the inhibition measure correlated significantly with math achievement scores, $r(58)=.254, p=.050$. To examine whether the NDE and RDE predicted unique variance in math achievement after more domain-general variables were incorporated into the model, scaled inhibition errors and working memory scores were added as predictors. The model was significant, and both the NDE and RDE still made unique contributions to the prediction of math achievement performance in the context of this model, $\mathrm{R}^{2}=.452, F(4,59)=11.33, p<$ $.001, \beta_{\mathrm{NDE}}=-.391, p<.001, \beta_{\mathrm{RDE}}=-.418, p<.001$, as did the scaled inhibition errors, $\beta_{\text {InhibitionErrors }}=.321, p=.002$.

In addition to considering the relationship between the distance effects and math achievement, general task performance in the two tasks was also correlated with math achievement. For this purpose, a performance measure using the following formula was calculated for the number comparison and ordinality tasks: $P=R T(1+2 E R)$, where RT was the average reaction time across the entire task for both the correct and incorrect trials, and ER was the error rate across the task $(E R=1-$ Accuracy $)$. One outlier participant each from the magnitude comparison and ordinality tasks was removed. The performance measures for ordering $(M=958.74, S D=284.10)$ and magnitude comparison $(M=496.15, S D=88.15)$ were significantly positively correlated, $r(56)=$ $.787, p<.001$. The performance measure for the ordinality task was significantly negatively correlated with all measures of math achievement, while the performance 
measure from the magnitude comparison task was only correlated with the Math Fluency measure and the Composite Score (See Table 4). Ordinality and cardinality performance were entered as predictors in a multiple regression analysis to predict the composite math score. Only ordinality was a significant predictor, $\mathrm{R}^{2}=.209, F(2,57)=7.26, p=.002$, $\beta_{\text {Cardinality }}=.235, p=.232, \beta_{\text {Ordinality }}=-.618, p=.002$. When ordinality and cardinality performance, standardized working memory and scaled inhibition error scores were entered into a multiple regression, ordinality performance was found to be the sole significant predictor, $\mathrm{R}^{2}=.271, F(4,57)=4.92, p=.002, \beta_{\text {Ordinality }}=-.616, p=.002$.

Table 4: Correlations between the performance measures from the cardinality and ordinality task and standardized scores for math achievement.

\begin{tabular}{lccc}
\hline & Math Fluency & Calculation & Composite \\
\hline Cardinality Performance & $-.310^{*}$ & -.242 & $-.269 *$ \\
Ordinality Performance & $-.422 * *$ & $-.383^{* *}$ & $-.419 * *$ \\
\hline
\end{tabular}

** Pearson correlation is significant at the 0.01 level (2-tailed).

* Pearson correlation is significant at the 0.05 level (2-tailed). 


\section{Chapter 4}

\section{Discussion}

Numerical symbols, such as Arabic numerals, can be processed as representations of numerical quantity (cardinality) or as elements within a numerical sequence (ordinality). Consequently researchers have sought to understand whether processing the cardinality and ordinality of numerical symbols relies on shared or distinct neurocognitive processes. The available evidence from both behavioural and neuroimaging studies that have aimed to address this question have yielded a mixed body of evidence. In the present study we sought to address this outstanding question by investigating whether effects derived from tasks measuring numerical comparison and numerical ordering are a) significantly correlated with one another, which would suggest a common underlying representation and b) whether they relate to individual differences in arithmetic in the same way or, consistent with the notion of separate representations, they independently relate to such outcome measures. While previous studies have reported different effects (i.e., NDE vs. RDE) in ordering, here we investigate for the first time whether these effects are related to one another in adults.

\subsection{No significant association between the NDE and RDE}

Contrary to the notion that processing the cardinality and ordinality of Arabic numerals relies on a shared mechanism, we found that the RDE from the ordinality task and the NDE from the cardinality task were not significantly correlated with one another. This suggests that the mechanisms underlying cardinal and ordinal processing are distinct in adults. 
This finding is in line with research by Turconi and colleagues (2004), as well as Lyons and Beilock (2013), who both found evidence for divergent neural processes underlying ordinal and cardinal processing. The present data are also consistent with those reported by Vogel and colleagues (2015), who demonstrated that cardinal and ordinal processes were not associated in a sample of children. Our findings add to this body of data, by demonstrating that cardinal and ordinal mechanisms remain distinct in adulthood. Therefore, it seems that processing symbolic numbers relies on different mechanisms from an early age onwards, depending on the operations that are being carried out (magnitude comparison vs. ordering).

Although Franklin and Jonides (2009) found common IPS activation for the NDE and $\mathrm{RDE}$, the data from the current study suggest that the NDE and RDE are driven by different underlying representations. Future fMRI studies could go beyond looking at whether the NDE and RDE activate similar neuronal regions to looking at whether the neural distance effects within those brain regions are actually correlated with one another. In other words, spatial overlap of activation in the brain does not necessarily mean that representational similarity can be inferred. For example, Lyons, Ansari, and Beilock (2015) found that although tasks using symbolic and non-symbolic (dot) number stimuli recruit similar neuronal regions, the patterns of activation were not associated with one another across the two number formats. Similarly, based on the behavioural dissociation between the NDE and RDE, we might predict that the overlapping neuronal distance effects in the IPS found by Franklin and Jonides (2009) could actually be uncorrelated with one another. 


\subsection{Cardinality and ordinality contribute uniquely to math achievement skills}

Another way of investigating whether processing the cardinality and ordinality of symbolic number is underlain by distinct processes is to investigate their relationships with individual differences in arithmetic. We found that both the RDE and NDE correlated with math achievement: a larger NDE or RDE was associated with poorer performance on the Calculation and Math Fluency tasks. This supports previous findings of associations between the NDE and math (De Smedt et al., 2013). More notably, the current study was the first to report an association between the RDE and math achievement, revealing that this reliable, task-specific measure of ordinal processing explains individual differences in math achievement. Critically, both the NDE and RDE accounted for unique variance in our math achievement measures, further supporting the notion that these effects index qualitatively different processes that each contribute to individual differences in arithmetic achievement. Consistent with these findings, recent evidence from children also demonstrated that ordinality and cardinality may have differing roles in more complex math skills across development. Specifically, as previously discussed, Vogel et al. (2015) found no association between an ordering task and math, while Lyons et al. (2014) captured a crossover in the relative importance of ordinality and cardinality skills in terms of predicting math achievement in grades one through six. We demonstrated that by adulthood both ordering and magnitude comparison skills are important in the context of mathematics. Aside from looking for a direct relationship between the effects from the cardinal and ordinal tasks, assessing whether they relate uniquely to a third variable (i.e., math achievement) can provide further evidence for dissociated mechanisms. The finding of a correlation between 
ordinality performance and Calculation, is further evidence of a dissociation between ordinality and cardinality tasks. Moreover, only the ordinality performance measure (and not the cardinality performance measure) was a unique predictor of mathematical skills. This finding also underlines the importance of understanding the mechanisms distance effects are accessing, and how these mechanisms might differ from the processes measured by overall task performance.

It is also of note that the relationships between math and both cardinality and ordinality could not be explained by the more domain-general variables included in our study. While a measure of inhibitory control was a significant predictor of math achievement in the context of ordinality, cardinality, and working memory, cardinality and ordinality remained unique predictors of math achievement. Thus, the processing of symbolic order and cardinality relates to math achievement independently of domaingeneral factors that have also been demonstrated to explain variability in math achievement (e.g., Dumontheil \& Klingberg, 2012, Hubber, Gilmore \& Cragg, 2014). Gilmore and colleagues (2013) found that the relationship between a nonsymbolic comparison task and math achievement could be better explained by inhibition than differences in number representational acuity. The current study revealed that this was not the case for the symbolic comparison task as the symbolic comparison task continued to predict unique variance in math achievement, even after a measure of inhibition skills was included.

Our visual-spatial working memory task was not associated with math abilities. Previous research has demonstrated that visual-spatial working memory is an important skill for mathematics (Dumontheil \& Klingberg, 2012). However, there is some evidence 
that this association between visual-spatial working memory and mathematics varies greatly between different working memory and math measures. For example, in adults, Hubber and colleagues (2014) found that a secondary task engaging the central executive decreased arithmetic performance more than a secondary visuo-spatial task. While the secondary visual-spatial working memory task impaired math performance, more general central-executive skills may be more important for mathematics skills. In children Alloway \& Passolunghi (2011) found that while visual-spatial working memory was predictive of math in seven-year-olds, in eight-year-olds this relationship was not significant. Instead, visual-spatial short-term memory predicted math abilities. Additionally, it is possible that previous studies demonstrating a link between working memory and math have confounded this relationship by using a working memory task of a numerical nature (for example Peng \& Fuchs, 2014). Further research is needed to probe the complex relationship between mathematical skills and visual-spatial working memory.

Although the NDE and RDE for the reaction time data were associated with math achievement, we did not find an association between math achievement and the accuracy NDE or RDE. This could perhaps be due to a ceiling effect in the accuracy data, as the average accuracy was quite high for both the ordinality and cardinality tasks (95\% and $96 \%$ respectively).

\subsection{Mechanisms underlying the NDE and RDE}

The present results raise questions regarding the differences in the mechanisms indexed by the NDE and RDE. Previously, it has been proposed that distance effects may reflect numerical magnitude processing and the imprecise manner of numerical 
representation (Moyer \& Landauer, 1967). However, if that is the case, then one should only see a distance effect in numerical tasks that rely on symbol-magnitude associations, such as the number comparison task. As is evident from the present findings and others, the ordering task, thought to be a measure of symbol-symbol associations as opposed to symbol-magnitude associations, also generates a (reverse) distance effect, which calls into question the idea of distance effects reflecting numerical magnitude processing (Vogel et al., 2015). It could be argued that participants might use a series of magnitude comparisons to complete the ordering task. However, this would not lead to a reversal of the distance effect, since consistent with the NDE, serial comparisons of number pairs separated by small distances should lead to longer RTs than comparison of pairs of numbers separated by relatively larger distances.

Additionally, distance effects have also been observed with the use of nonnumerical ordered symbols, such as letters (Jou \& Aldridge, 1999; Van Opstal, Gevers, De Moor, \& Verguts, 2008). For example, Van Opstal and colleagues (2008) showed that the NDE could be obtained with letters, which have no magnitude associations. Using a letter comparison task where, analogous to the number comparison task, the letter higher in the alphabet must be selected, the higher letter was selected faster when the distance between the target letters was greater. Therefore the NDE, which can be obtained with non-numerical symbol stimuli, is not necessarily indicative of overlapping representations of numerical magnitude. Thus, it has been suggested that some distance effects arise from processes related to the decision process and the resolution of response alternatives, rather than arising from overlapping representations of cardinal numbers (Van Opstal et al., 2008). 
This is also important to bear in mind when interpreting the correlations with math performance. Specifically, it was found that both the NDE and RDE correlated negatively with the math outcome variables. This suggests that individuals who are less susceptible to the influence of distance in both judgements of symbolic cardinality and ordinality perform better on a standardized test of math achievement. Previously, a smaller NDE has been argued to reflect greater representational precision of the cardinality of number symbols (De Smedt et al., 2009; Holloway \& Ansari, 2009). However, an account based on the representational precision of the cardinality of number symbols cannot hold for the RDE because a) this effect exhibits the reverse of what would be predicted from a representational precision account (numbers that are close overlap more) and b) RDEs and NDEs, despite being both reliable, were found to be uncorrelated in the present study. Instead, it is plausible that both a smaller RDE and NDE, while stemming from distinct ordinal and cardinal representations, are reflective of less demand on decision making processes. While the present study remains agnostic as to the precise differences in the processes and representations giving rise to the NDE and $\mathrm{RDE}$, the findings do demonstrate the processes that drive these two effects are qualitatively different and relate differentially to math achievement.

Notwithstanding the need to further pinpoint the exact meaning of NDEs and RDEs it is also important to note that a key finding regarding the differential correlations with math holds, even when considering task performance in ordinality and cardinality judgements independently of distance effects. Specifically, we found that general performance (a combined measure of RT and accuracy, see above) on these tasks was differentially related to arithmetic performance and, moreover, a multiple regression 
analysis revealed that performance on the ordinality task was a unique predictor of arithmetic, while comparison was not.

\subsection{Conclusions}

In summary, we found that the distance effects generated from a symbolic ordinality and cardinality task were not significantly associated with one another in adults. Additionally, both effects were uniquely predictive of math achievement scores, even in the context of domain-general variables such as visual-spatial working memory and inhibitory control. These results support the idea of distinct mechanisms underlying cardinal and ordinal processing of symbolic numerals in adults. Both magnitude comparison and ordering skills explained unique variance in math achievement, thereby further demonstrating the dissociated nature of these constructs, as well as their independent importance for more complex mathematical skills. These findings call for a greater investigation into the multiple levels at which symbolic numbers can be processed, and how these processes in turn relate to math achievement. 


\section{References}

Alloway, T. T. (2007). Automated Working Memory Assessment. San Antonio, TX: Psychological Corporation.

Alloway, T. P., \& Passolunghi, M. C. (2011). The relationship between working memory, IQ, and mathematical skills in children. Learning and Individual Differences, 21(1), 133-137. doi:10.1016/j.lindif.2010.09.013

Ansari, D. (2008). Effects of development and enculturation on number representation in the brain. Nature Reviews. Neuroscience, 9(4), 278-91. doi:10.1038/nrn2334

Castronovo, J., \& Göbel, S. M. (2012). Impact of High Mathematics Education on the Number Sense. PLoS ONE, 7(4), e33832. doi:10.1371/journal.pone.0033832

De Smedt, B., Noël, M.-P., Gilmore, C., \& Ansari, D. (2013). How do symbolic and nonsymbolic numerical magnitude processing skills relate to individual differences in children's mathematical skills? A review of evidence from brain and behavior. Trends in Neuroscience and Education, 2(2), 48-55. doi:10.1016/j.tine.2013.06.001

De Smedt, B., Verschaffel, L., \& Ghesquière, P. (2009). The predictive value of numerical magnitude comparison for individual differences in mathematics achievement. Journal of Experimental Child Psychology, 103(4), 469-479. doi:10.1016/j.jecp.2009.01.010

Delis, D. C., Kaplan, E., \& Kramer, J. H. (2001). Delis-Kaplan Executive Function System. San Antonio, TX: The Psychological Corporation

Dumontheil, I., \& Klingberg, T. (2012). Brain activity during a visuospatial working memory task predicts arithmetical performance 2 years later. Cerebral Cortex, 22(May), 1078-1085. doi:10.1093/cercor/bhr175 
Franklin, M. S., \& Jonides, J. (2009). Order and magnitude share a common representation in parietal cortex. Journal of Cognitive Neuroscience, 21(2006), 2114-2120. doi:10.1162/jocn.2008.21181

Gilmore, C., Attridge, N., Clayton, S., Cragg, L., Johnson, S., Marlow, N., ... Inglis, M. (2013). Individual differences in inhibitory control, not non-verbal number acuity, correlate with mathematics achievement. PloS One, 8(6), e67374. doi:10.1371/journal.pone.0067374

Holloway, I. D., \& Ansari, D. (2008). Domain-specific and domain-general changes in children's development of number comparison. Developmental Science, 11(5), 6449. doi:10.1111/j.1467-7687.2008.00712.x

Holloway, I. D., \& Ansari, D. (2009). Mapping numerical magnitudes onto symbols: the numerical distance effect and individual differences in children's mathematics achievement. Journal of Experimental Child Psychology, 103(1), 17-29. doi:10.1016/j.jecp.2008.04.001

Holloway, I. D., Battista, C., Vogel, S. E., \& Ansari, D. (2013). Semantic and perceptual processing of number symbols: evidence from a cross-linguistic fMRI adaptation study. Journal of Cognitive Neuroscience, 25(3), 388-400. doi:10.1162/jocn_a_00323

Hubber, P. J., Gilmore, C., \& Cragg, L. (2014). The roles of the central executive and visuospatial storage in mental arithmetic: a comparison across strategies. Quarterly Journal of Experimental Psychology (2006), 67(5), 936-54. doi:10.1080/17470218.2013.838590

Jou, J., \& Aldridge, J. W. (1999). Memory representation of alphabetic position and interval information. Journal of Experimental Psychology: Learning, Memory, and Cognition, 25(3), 680-701. doi:10.1037//0278-7393.25.3.680 
Knops, A., \& Willmes, K. (2014). Numerical ordering and symbolic arithmetic share frontal and parietal circuits in the right hemisphere. NeuroImage, 84(2014), 786795. doi:10.1016/j.neuroimage.2013.09.037

Lonnemann, J., Linkersdörfer, J., Hasselhorn, M., \& Lindberg, S. (2011). Symbolic and non-symbolic distance effects in children and their connection with arithmetic skills. Journal of Neurolinguistics, 24(5), 583-591. doi:10.1016/j.jneuroling.2011.02.004

Lyons, I. M., Ansari, D., \& Beilock, S. L. (2015). Qualitatively different coding of symbolic and nonsymbolic numbers in the human brain. Human Brain Mapping, 36(2), 475-488. doi:10.1002/hbm.22641

Lyons, I. M., \& Beilock, S. L. (2011). Numerical ordering ability mediates the relation between number-sense and arithmetic competence. Cognition, 121(2), 256-61. doi:10.1016/j.cognition.2011.07.009

Lyons, I. M., \& Beilock, S. L. (2013). Ordinality and the nature of symbolic numbers. The Journal of Neuroscience, 33(43), 17052-61. doi:10.1523/JNEUROSCI.177513.2013

Lyons, I. M., Price, G. R., Vaessen, A., Blomert, L., \& Ansari, D. (2014). Numerical predictors of arithmetic success in grades 1-6. Developmental Science, 17(5), 71426. doi:10.1111/desc. 12152

Maloney, E. a, Risko, E. F., Preston, F., Ansari, D., \& Fugelsang, J. (2010). Challenging the reliability and validity of cognitive measures: the case of the numerical distance effect. Acta Psychologica, 134(2), 154-61. doi:10.1016/j.actpsy.2010.01.006

Moyer, R. S., \& Landauer, T. K. (1967). Time required for judgements of numerical inequality. Nature, 215(5109), 1519-20. Retrieved from http://www.ncbi.nlm.nih.gov/pubmed/6052760

Nieder, A. (2005). Counting on neurons: the neurobiology of numerical competence. Nature Reviews. Neuroscience, 6(March), 177-190. doi:10.1038/nrn1626 
Nieder, A., \& Dehaene, S. (2009). Representation of number in the brain. Annual Review of Neuroscience, 32, 185-208. doi:10.1146/annurev.neuro.051508.135550

Peng, P., \& Fuchs, D. (2014). A Meta-Analysis of Working Memory Deficits in Children With Learning Difficulties: Is There a Difference Between Verbal Domain and Numerical Domain? Journal of Learning Disabilities. doi: $10.1177 / 0022219414521667$

Sasanguie, D., De Smedt, B., Defever, E., \& Reynvoet, B. (2012). Association between basic numerical abilities and mathematics achievement. The British Journal of Developmental Psychology, 30(Pt 2), 344-57. doi:10.1111/j.2044835X.2011.02048.x

Sasanguie, D., Defever, E., Van den Bussche, E., \& Reynvoet, B. (2011). The reliability of and the relation between non-symbolic numerical distance effects in comparison, same-different judgments and priming. Acta Psychologica, 136(1), 73-80. doi:10.1016/j.actpsy.2010.10.004

Sekuler, R., \& Mierkiewicz, D. (1977). Children's Judgments of Numerical Inequality. Child Development, 48, 630. doi:10.2307/1128664

Swanson, H. L. (2011). Working memory, attention, and mathematical problem solving: A longitudinal study of elementary school children. Journal of Educational Psychology, 103(4), 821-837. doi:10.1037/a0025114

Turconi, E., Campbell, J. I. D., \& Seron, X. (2006). Numerical order and quantity processing in number comparison. Cognition, 98(2006), 273-285. doi:10.1016/j.cognition.2004.12.002

Turconi, E., Jemel, B., Rossion, B., \& Seron, X. (2004). Electrophysiological evidence for differential processing of numerical quantity and order in humans. Cognitive Brain Research, 21(2004), 22-38. doi:10.1016/j.cogbrainres.2004.05.003

Van Opstal, F., Gevers, W., De Moor, W., \& Verguts, T. (2008). Dissecting the symbolic distance effect: comparison and priming effects in numerical and nonnumerical 
orders. Psychonomic Bulletin \& Review, 15(2), 419-25. Retrieved from http://www.ncbi.nlm.nih.gov/pubmed/18488662

Vogel, S. E., Remark, A., \& Ansari, D. (2015). Differential processing of symbolic numerical magnitude and ordr in 1st grade children. Journal of Experimental Child Psychology, 129(2015), 26-39. doi:10.1016/j.jecp.2014.07.010

Woodcock, R. W., McGrew, K. S., \& Mather, N. (2001) Woodcock-Johnson III Tests of Achievement. Itasca, IL: Riverside Publishing. 


\section{Appendices}

\section{Appendix A: Ethics Approval}

Western

Research Ethics

Research

Western University Health Science Research Ethics Board NMREB Delegated Initial Approval Notice

Principal Investigator: Prof. Daniel Ansari

Department \& Institution: Social SciencelPsychology, Western University

NMREB File Number: 105418

Study Title: Reliability and validity of tasks commonly used in numerical cognition research Sponsor:

NMREB Initial Approval Date: June 26, 2014

NMREB Expiry Date: May 31, 2015

Documents Approved and/or Received for Information

\begin{tabular}{|l|l|l|}
\hline Document Name & Comments & Version Date \\
\hline Instruments & New Instrument: Demographic Information & $2014 / 05 / 28$ \\
\hline Instruments & Standard instrument: Woodcock Johnson Math Fluency & $2014 / 05 / 29$ \\
\hline Instruments & Standard instrument: Woodcock Johnson Calculation & $2014 / 05 / 29$ \\
\hline Instruments & Standard instrument: AWMA Odd One Out & $2014 / 05 / 29$ \\
\hline Recruitment Items & Standard instrument: D-KEFS Colour-Word Interference & $2014 / 05 / 29$ \\
\hline Letter of Information \& Consent & Email & $2014 / 06 / 18$ \\
\hline Recruitment Items & Poster & $2014 / 06 / 18$ \\
\hline Western University Protocol & & $2014 / 06 / 18$ \\
\hline Instruments & New Instruments: Computerized Measures & $2014 / 06 / 18$ \\
\hline
\end{tabular}

The Western University Non-Medical Research Ethics Board (NMREB) has reviewed and approved the above named study, as of the HSREB Initial Approval Date noted above.

NMREB approval for this study remains valid until the NMREB Expiry Date noted above, conditional to timely submission and acceptance of HSREB Continuing Ethics Review.

The Western University NMREB operates in compliance with the Tri-Council Policy Statement Ethical Conduct for Research Involving Humans (TCPS2), the Ontario Personal Health Information Protection Act (PHIPA, 2004), and the applicable laws and regulations of Ontario.

Members of the NMREB who are named as Investigators in research studies do not participate in discussions related to, nor vote on such studies when they are presented to the REB.

The NMREB is registered with the U.S. Department of Health \& Human Services under the IRB registration number IRB 00000941

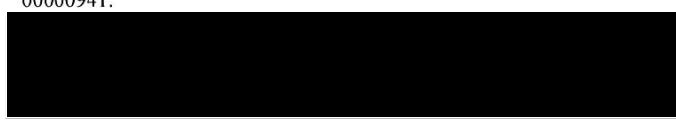

Ethics Officer to Contact for Further Information

\begin{tabular}{|c|c|c|c|}
\hline \begin{tabular}{|l} 
Erika Basile \\
ebasile@uwo.ca
\end{tabular} & \begin{tabular}{|c|} 
Grace Kelly \\
grace.kelly@uwo.ca
\end{tabular} & $\begin{array}{c}\text { Thina Mekhail } \\
\text { mmekhail@uwo.ca }\end{array}$ & $\begin{array}{l}\text { Vikki Tran } \\
\text { vikki.tran@uwo.ca }\end{array}$ \\
\hline
\end{tabular}

This is an official document. Please retain the original in your files.

Western University, Research, Support Services Bldg.. Rm. 5150

London. ON. Canada N6A 3K7 t. 519.661.3036 f. 519.850.2466 www.uwo.ca/research/services/ethics 


\section{Western University Health Science Research Ethics Board NMREB Amendment Approval Notice}

Principal Investigator: Prof. Daniel Ansari

Department \& Institution: Social SciencelPsychology, Western University

NMREB File Number: 105418

Study Title: Reliability and validity of tasks commonly used in numerical cognition research Sponsor:

NMREB Revision Approval Date: October 03, 2014

NMREB Expiry Date: May 31, 2015

Documents Approved and/or Received for Information:

Document Name Comments Version Date

\begin{tabular}{|l|l|l|l}
\hline Revised Western University Protocol & Sample size change (from 50 to 100) 2014/09/17
\end{tabular}

\begin{tabular}{|l|l|l|l|}
\hline Revised Letter of Information \& Consent & Sample size change (from 50 to 100) 2014/09/17
\end{tabular}

Recruitment Items Sample size change (from 50 to 100 ) $2014 / 09 / 17$

The Western University Non-Medical Science Research Ethics Board (NMREB) has reviewed and approved the amendment to the above named study, as of the NMREB Amendment Approval Date noted above.

NMREB approval for this study remains valid until the NMREB Expiry Date noted above, conditional to timely submission and acceptance of HSREB Continuing Ethics Review.

The Western University NMREB operates in compliance with the Tri-Council Policy Statement Ethical Conduct for Research Involving Humans (TCPS2), the Ontario Personal Health Information Protection Act (PHIPA, 2004), and the applicable laws and regulations of Ontario

Members of the NMREB who are named as Investigators in research studies do not participate in discussions related to, nor vote on such studies when they are presented to the REB.

The NMREB is registered with the U.S. Department of Health \& Human Services under the IRB registration number IRB 00000941 .

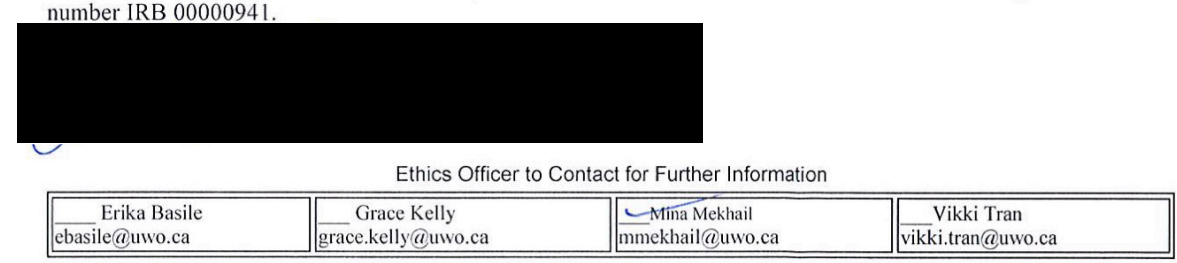

This is an official document. Please retain the original in your files. 


\section{Appendix B: Cardinality Task Trial List}

\begin{tabular}{|c|c|c|c|c|c|}
\hline Left Number & $\begin{array}{c}\text { Right } \\
\text { Number }\end{array}$ & Distance & Left Number & $\begin{array}{c}\text { Right } \\
\text { Number }\end{array}$ & Distance \\
\hline 3 & 4 & 1 & 4 & 3 & 1 \\
\hline 6 & 7 & 1 & 7 & 6 & 1 \\
\hline 2 & 3 & 1 & 3 & 2 & 1 \\
\hline 4 & 5 & 1 & 5 & 4 & 1 \\
\hline 7 & 8 & 1 & 8 & 7 & 1 \\
\hline 5 & 6 & 1 & 6 & 5 & 1 \\
\hline 2 & 4 & 2 & 4 & 2 & 2 \\
\hline 4 & 6 & 2 & 6 & 4 & 2 \\
\hline 7 & 9 & 2 & 9 & 7 & 2 \\
\hline 5 & 7 & 2 & 7 & 5 & 2 \\
\hline 6 & 8 & 2 & 8 & 6 & 2 \\
\hline 3 & 5 & 2 & 5 & 3 & 2 \\
\hline 2 & 5 & 3 & 5 & 2 & 3 \\
\hline 4 & 7 & 3 & 7 & 4 & 3 \\
\hline 5 & 8 & 3 & 8 & 5 & 3 \\
\hline 3 & 6 & 3 & 6 & 3 & 3 \\
\hline 4 & 7 & 3 & 7 & 4 & 3 \\
\hline 6 & 9 & 3 & 9 & 6 & 3 \\
\hline 2 & 6 & 4 & 6 & 2 & 4 \\
\hline 5 & 9 & 4 & 9 & 5 & 4 \\
\hline 3 & 7 & 4 & 7 & 3 & 4 \\
\hline 1 & 5 & 4 & 5 & 1 & 4 \\
\hline 4 & 8 & 4 & 8 & 4 & 4 \\
\hline 2 & 6 & 4 & 6 & 2 & 4 \\
\hline 2 & 7 & 5 & 7 & 2 & 5 \\
\hline 3 & 8 & 5 & 8 & 3 & 5 \\
\hline 4 & 9 & 5 & 9 & 4 & 5 \\
\hline 2 & 7 & 5 & 7 & 2 & 5 \\
\hline 1 & 6 & 5 & 6 & 1 & 5 \\
\hline 3 & 8 & 5 & 8 & 3 & 5 \\
\hline 1 & 7 & 6 & 7 & 1 & 6 \\
\hline 2 & 8 & 6 & 8 & 2 & 6 \\
\hline 3 & 9 & 6 & 9 & 3 & 6 \\
\hline 1 & 7 & 6 & 7 & 1 & 6 \\
\hline 2 & 8 & 6 & 8 & 2 & 6 \\
\hline 3 & 9 & 6 & 9 & 3 & 6 \\
\hline
\end{tabular}


Appendix C: Ordinality Task Trial List

In Order Trials

\begin{tabular}{|cccc|}
\hline $\begin{array}{c}\text { Left } \\
\text { Number }\end{array}$ & $\begin{array}{c}\text { Middle } \\
\text { Number }\end{array}$ & $\begin{array}{c}\text { Right } \\
\text { Number }\end{array}$ & Distance \\
\hline 1 & 2 & 3 & 1 \\
2 & 3 & 4 & 1 \\
3 & 4 & 5 & 1 \\
4 & 5 & 6 & 1 \\
5 & 6 & 7 & 1 \\
6 & 7 & 8 & 1 \\
7 & 8 & 9 & 1 \\
1 & 3 & 5 & 2 \\
2 & 4 & 6 & 2 \\
3 & 5 & 7 & 2 \\
4 & 6 & 8 & 2 \\
5 & 7 & 9 & 2 \\
1 & 4 & 7 & 3 \\
2 & 5 & 8 & 3 \\
3 & 6 & 9 & 3 \\
\hline
\end{tabular}


Not In Order Trials

\begin{tabular}{|c|c|c|c|c|c|c|c|}
\hline $\begin{array}{c}\text { Left } \\
\text { Number }\end{array}$ & $\begin{array}{c}\text { Middle } \\
\text { Number }\end{array}$ & $\begin{array}{c}\text { Right } \\
\text { Number }\end{array}$ & Distance & $\begin{array}{c}\text { Left } \\
\text { Number }\end{array}$ & $\begin{array}{c}\text { Middle } \\
\text { Number }\end{array}$ & $\begin{array}{c}\text { Right } \\
\text { Number }\end{array}$ & Distance \\
\hline 2 & 1 & 3 & 1 & 2 & 3 & 1 & 1 \\
\hline 3 & 2 & 4 & 1 & 3 & 4 & 2 & 1 \\
\hline 4 & 3 & 5 & 1 & 4 & 5 & 3 & 1 \\
\hline 5 & 4 & 6 & 1 & 5 & 6 & 4 & 1 \\
\hline 6 & 5 & 7 & 1 & 6 & 7 & 5 & 1 \\
\hline 7 & 6 & 8 & 1 & 7 & 8 & 6 & 1 \\
\hline 8 & 7 & 9 & 1 & 8 & 9 & 7 & 1 \\
\hline 3 & 1 & 5 & 2 & 3 & 5 & 1 & 2 \\
\hline 4 & 2 & 6 & 2 & 4 & 6 & 2 & 2 \\
\hline 5 & 3 & 7 & 2 & 5 & 7 & 3 & 2 \\
\hline 6 & 4 & 8 & 2 & 6 & 8 & 4 & 2 \\
\hline 7 & 5 & 9 & 2 & 7 & 9 & 5 & 2 \\
\hline 4 & 1 & 7 & 3 & 4 & 7 & 1 & 3 \\
\hline 5 & 2 & 8 & 3 & 5 & 8 & 2 & 3 \\
\hline 6 & 3 & 9 & 3 & 6 & 9 & 3 & 3 \\
\hline 1 & 3 & 2 & 1 & 3 & 1 & 2 & 1 \\
\hline 2 & 4 & 3 & 1 & 4 & 2 & 3 & 1 \\
\hline 3 & 5 & 4 & 1 & 5 & 3 & 4 & 1 \\
\hline 4 & 6 & 5 & 1 & 6 & 4 & 5 & 1 \\
\hline 5 & 7 & 6 & 1 & 7 & 5 & 6 & 1 \\
\hline 6 & 8 & 7 & 1 & 8 & 6 & 7 & 1 \\
\hline 7 & 9 & 8 & 1 & 9 & 7 & 8 & 1 \\
\hline 1 & 5 & 3 & 2 & 5 & 1 & 3 & 2 \\
\hline 2 & 6 & 4 & 2 & 6 & 2 & 4 & 2 \\
\hline 3 & 7 & 5 & 2 & 7 & 3 & 5 & 2 \\
\hline 4 & 8 & 6 & 2 & 8 & 4 & 6 & 2 \\
\hline 5 & 9 & 7 & 2 & 9 & 5 & 7 & 2 \\
\hline 1 & 7 & 4 & 3 & 7 & 1 & 4 & 3 \\
\hline 2 & 8 & 5 & 3 & 8 & 2 & 5 & 3 \\
\hline 3 & 9 & 6 & 3 & 9 & 3 & 6 & 3 \\
\hline
\end{tabular}




\section{Curriculum Vitae}

\section{Name: \\ Post-secondary Education and Degrees:}

\section{Honours and Awards}

Related Work Experience
Celia Goffin

The University of Western Ontario

London, Ontario, Canada

2014-present M.Sc.

The University of Western Ontario

London, Ontario, Canada

2008-2012 B.A. (Honors)

National Sciences and Engineering Research Council of Canada (NSERC)

PGS-D

2015-2018

Social Science and Humanities Research Council (SSHRC) CGS-M

2015

Ontario Graduate Scholarship (OGS; offered) 2015

McClelland Award for best $4^{\text {th }}$ year psychology thesis 2012

Dean's Honor List

2011-2012

Teaching Assistant

The University of Western Ontario

2013-2015

Research Assistant (Dr. Ansari)

Department of Psychology

The University of Western Ontario 2012-2013

Developmental Recruitment at Victoria Hospital Department of Psychology

The University of Western Ontario 2011-2013 


\section{Publications}

Vogel, S. E., Goffin, C. \& Ansari, D. (2015). Developmental specialization of the left parietal cortex for the semantic representation of Arabic numerals: An fMRAdaptation study. Developmental Cognitive Neuroscience, 12(2015), 61-73.

\section{Oral Presentations}

Goffin, C., Vogel, S. \& Ansari, D. (2014). Reliability and validity of effects commonly used in numerical cognition research. Numerical Cognition Research Retreat, Bayfield, Canada.

Goffin, C. \& Ansari, D. (2014). Numerical cognition in children with cerebral palsy. Paediatric Neuroscience Rounds, Thames Valley Children's Centre, London, Canada.

Vogel, S. E., Goffin, C \& Ansari, D (2013). Entwicklungsbedingte Veränderungen der neuronalen Korrelate für die Repräsentation symbolischer Zahlenmenge (Developmental changes of the neural correlates associated with symbolic numerical magnitude representation). Fachgruppentagung für Pädagogische Psychologie, Hildesheim, Germany.

\section{Poster Presentations}

Goffin, C. \& Ansari, D. (2015). Measuring symbolic numerical processing in adults. NIH Math Cognition and Learning Conference, St. Louis, U.S.

Goffin, C. \& Ansari, D. (2015). Measuring symbolic numerical processing in adults. Lake Ontario Visionary Establishment (LOVE), Niagara Falls, Canada.

Goffin, C., Vogel, S. E., \& Ansari, D. (2014). Reliability and convergent validity of the numerical distance, priming distance and congruency effects. Minds on Minds Symposium, London, Canada.

Goffin, C., Vogel, S. E., \& Ansari, D. (2014). Reliability and validity of effects commonly used in numerical cognition research. Banff Annual Seminar in Cognitive Science (BASICS), Banff, Canada.

Vogel, S. E., Goffin, C. \& Ansari, D. (2013). Developmental changes in the cortical representation underlying the semantic processing of numerical symbols. Brain Plasticity, Learning, and Education Symposium, London, Canada. 